\title{
HEPATITIS
}

\section{Prognostic determinants for chronic hepatitis B in Asians: therapeutic implications}

\author{
M-F Yuen, H-J Yuan, D K-H Wong, J C-H Yuen, W-M Wong, A O-O Chan, \\ B C-Y Wong, K-C Lai, C-L Lai
}

See end of article for authors' affiliations

\section{Correspondence to:} Professor C-L Lai,

Department of Medicine, The University of Hong Kong, Queen Mary Hospital, Pokfulam Rd, Hong Kong, China; hrmelcl@hkucc.hku.hk

Revised version received 13 March 2005

Accepted for publication 19 April 2005

Published online first

4 May 2005
Background: Identifying risk factors for the development of complications of chronic hepatitis B (CHB) is important for setting up treatment criteria.

Aim: To determine risk factors for the development of complications in Asian CHB patients.

Patients and methods: A total of 3233 Chinese CHB patients (mean follow up 46.8 months) were monitored for liver biochemistry, viral serology, hepatitis B virus (HBV) DNA levels, acute exacerbation, hepatitis $B$ e antigen ( $\mathrm{HBeAg}$ ) seroconversion, and development of cirrhotic complications and hepatocellular carcinoma.

Results: Median age for $\mathrm{HBeAg}$ seroconversion and development of complications was 35 years and 57.2 years, respectively. Patients with alanine aminotransferase (ALT) levels of $0.5-1$ times the upper limit of normal (ULN) and 1-2× ULN had an increased risk for the development of complications compared with patients with ALT levels $<0.5 \times \mathrm{ULN}$ ( $p<0.0001$ for both). HBeAg/antibody to hepatitis B e antigen status, and number of episodes, duration, and peak ALT levels of acute exacerbations were not associated with an increased risk of complications. In patients with complications, $43.6 \%$ had HBV DNA levels less than $1.42 \times 10^{5}$ copies $/ \mathrm{ml}$. Male sex, stigmata of chronic liver disease, old age, low albumin, and high $\alpha$ fetoprotein levels on presentation were independently associated with increased cumulative risk of complications. Male sex, presence of hepatitis symptoms, old age, low albumin level, and presence of complications on presentation were independently associated with shorter survival.

Conclusion: Prolonged low level viraemia causing insidious and continual liver damage, as reflected by ALT levels of $0.5-2 \times$ ULN, is the most likely pathway for the development of complications in Asian CHB patients.
C hronic hepatitis B (CHB) virus infection affects more than 400 million people globally, of whom $75 \%$ are Asians $^{12}: 25-40 \%$ of chronic CHB patients will develop complications of cirrhosis and hepatocellular carcinoma (HCC).$^{3}$ Although there have been marked advances in the therapeutic options for CHB recently, indications for treatment remain controversial. Guidelines from the American Association for the Study of Liver Diseases, European Association of the Study of Liver, and Asian-Pacific Association of the Study of Liver suggest that treatment should only be given when there is persistent elevated alanine aminotransferase (ALT) levels $>2$ times normal and hepatitis B virus (HBV) DNA levels of $>10^{5}$ copies $/ \mathrm{ml}$ for both hepatitis $\mathrm{B}$ e antigen (HBeAg) positive and negative patients. ${ }^{5-7}$ However, no study has proved that patients with values below these arbitrarily defined cut off levels are at a lower risk for the development of cirrhosis related complications or HCC. In fact, a recent study by Kim et al in the general population of Korea found that there was already an increased risk of mortality from liver disease in patients with ALT levels in the upper range of normal. ${ }^{8}$ It is essential that more evidence for establishing treatment criteria should be sought, especially as more potent and safe therapeutic agents will be available in the near future. ${ }^{9} 10$

The aim of the present large scale study was to examine the factors determining the development of cirrhosis related complications and survival in Asian CHB patients.

\section{PATIENTS AND METHODS}

All Chinese CHB patients who were followed up in the Hepatitis Clinic, Department of Medicine, Queen Mary
Hospital, Hong Kong, during the period from January 1976 to December 2000 were recruited. A total of 346 patients who already had cirrhosis related complications including ascites, spontaneous bacterial peritonitis (SBP), oesophageal varices, encephalopathy, or HCC (collectively termed as "complications") on presentation were excluded from the study. Patients with hepatitis $C(n=25)$ and hepatitis D $(n=10)$ coinfection, a history of significant alcohol consumption $(n=19)$, evidence of coexisting autoimmune hepatitis $(n=4)$, Wilson's disease $(n=5)$, or primary biliary cirrhosis $(n=5)$ were also excluded. In addition, 494 patients who received interferon, lamivudine, or other investigational modalities for the treatment of CHB were excluded because these would not represent the natural history of the disease. The long term outcome of interferon treated patients has been analysed and published separately. ${ }^{11}$ All of the studies of interferon included patients with normal as well as elevated ALT levels. Their exclusion should not bias the outcome of our current analysis.

All patients were positive for hepatitis B surface antigen by micro-particle enzyme immunoassay (MEIA; Abbott Laboratories, Chicago, Illinois, USA) for at least six months. HBeAg and antibodies to HBeAg (anti-HBe) (ELISA; Abbott Laboratories), liver biochemistry, and $\alpha$ fetoprotein (AFP) were checked every 3-6 months. Continual clinical assessments, including the development of ascites, were carried out

Abbreviations: $\mathrm{CHB}$, chronic hepatitis $B ; \mathrm{HBV}$, hepatitis $B$ virus; $A L T$, alanine aminotransferase; ULN, upper limit of normal; HCC, hepatocellular carcinoma; $\mathrm{HBeAg}$, hepatitis $\mathrm{B}$ e antigen; SBP, spontaneous bacterial peritonitis; anti-HBe, antibody to hepatitis $B$ e antigen; AFP, $\alpha$ fetoprotein; PCR, polymerase chain reaction 
Table 1 Demographic data of the 3233 patients on presentation

\begin{tabular}{lc}
\hline No of patients & 3233 \\
Sex ratio (M:F) & $2121: 1112(1.9: 1)$ \\
Age (y) (median (range)) & $38(1-85)$ \\
HBeAg: anti-HBe & $1274: 1959(1: 1.5)$ \\
Albumin (g/l) (median (range)) & $45(15-58)$ \\
Bilirubin ( $\mu$ mol/I) (median (range)) & $11.8(1-55.3)$ \\
ALT (U/I) (median (range)) & $42(4-4820)$ \\
No of patients with & $714(22.1 \%)$ \\
ALT $\leqslant 0.5 \times$ ULN & $1006(31.1 \%)$ \\
ALT $>0.5-1 \times$ ULN & $737(22.8 \%)$ \\
ALT $1-2 \times$ ULN & $479(14.8 \%)$ \\
ALT $>2-6 \times$ ULN & $297(9.2 \%)$ \\
ALT $>6 \times$ ULN & $2861(88.5 \%)$ \\
No of patients with & $243(7.5 \%)$ \\
AFP $\leqslant 20 \mathrm{ng} / \mathrm{ml}$ & $97(3 \%)$ \\
AFP $>20-100 \mathrm{ng} / \mathrm{ml}$ & $32(1 \%)$ \\
AFP $>100-500 \mathrm{ng} / \mathrm{ml}$ & \\
AFP $>500 \mathrm{ng} / \mathrm{ml}$ & $29(6-291)$ \\
Duration of follow up (months) & $46.9(46.6)$ \\
Median (range) & \\
Mean (SD) & \\
\hline HBeAg, hepatitis B e antigen; anti-HBe, antibody to hepatitis B e antigen; \\
ALT, alanine aminotransferase; ULN, upper limit of normal; AFP, $\alpha$ \\
fetoprotein.
\end{tabular}

during each follow up. Patients with significant symptoms or abnormalities in blood tests were recalled and, if necessary, admitted to hospital. HBV DNA levels were measured by the Digene Hybrid Capture assay (Digene Corporation, Gaithersburg, Maryland, USA; lower limit of detection 140000 copies $/ \mathrm{ml}$ ). In order to determine HBV DNA levels at relatively low titre, HBV DNA levels of all anti-HBe positive patients were determined again using a polymerase chain reaction (PCR) based assay (Cobas Amplitor HBV Monitor Test; Roche Diagnostics, Branchburg, New Jersey; lower limit of detection 200 copies $/ \mathrm{ml}$ ).

Patients with ALT levels that were increased to 1.5 times the upper limit of normal (ULN) (upper limit: 53 and $31 \mathrm{U} / \mathrm{l}$ for males and females, respectively) were defined as having exacerbation of chronic HBV infection if other common causes of ALT elevation were excluded, including other viral hepatitis, drug induced hepatitis, alcoholic hepatitis, and steatohepatitis. Peak ALT, peak bilirubin, peak AFP levels, and duration for each exacerbation were noted.

HBeAg seroconversion was defined as loss of HBeAg with development of anti-HBe on at least two consecutive follow up visits.

Ultrasonogram was arranged for patients with elevated AFP $(>20 \mathrm{ng} / \mathrm{ml})$ if ALT was normal and for patients with persistently elevated AFP even if ALT was raised. Computer tomography and/or hepatic angiogram was performed if ultrasound showed suspicion of HCC. For patients with clinical detection of ascites, splenomegaly, or persistently low albumin of $<35 \mathrm{~g} / \mathrm{l}$, a screening oesophageogastroduodenoscopy was performed for detection of oesophageal varices. The occurrence of complications and survival time were recorded.

\section{Statistical analysis}

All statistical analyses were performed using the Statistical Program for Social Sciences (SPSS 10.0 for Windows; SPSS Inc., Chicago, Illinois, USA). Normality of the distribution of continuous variables was tested by the Komolgorov-Smirnov test. The Mann-Whitney $U$ test was used for continuous variables with skewed distribution and the $\chi^{2}$ test with Yates' correction factor or Fisher's exact test was applied for categorical variables. Differences in paired parameters were tested by the Wilcoxon signed ranks test. The Kaplan-Meier method using the log rank test was applied for calculation of

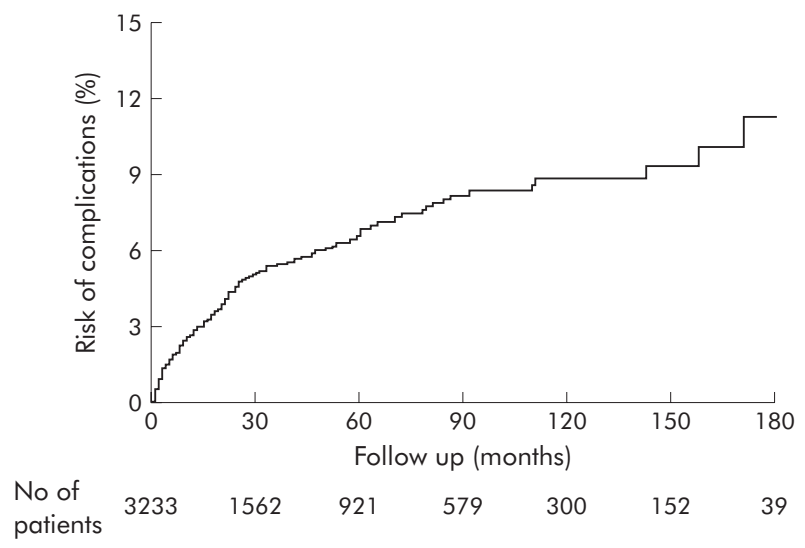

Figure 1 Cumulative risk of development of complications of the study population.

the cumulative risk of development of complications and survival. The Cox hazard proportional model was used to test the associations between different variables and the development of complications and survival.

\section{RESULTS}

\section{Demographics}

A total of 3233 HBV patients were recruited. Demographic data on presentation are shown in table 1. Median and mean duration of follow up were 29 (range 6-291) months and 46.9 (SD 46.6) months, respectively.

\section{$\mathrm{HBeAg}$ seroconversion}

Among 1274 patients positive for HBeAg on presentation, 512 patients $(40.2 \%)$ had HBeAg seroconversion at subsequent follow up. Median age at HBeAg seroconversion was 35 years (range 3.6-77.4).

\section{Development of complications}

A total of 170 patients $(5.3 \%)$ developed at least one complication. The number of patients developing each complication was as follows: ascites 96 (3.0\%) with 30 patients $(0.9 \%)$ also having SBP, oesophageal varices 59 ( $1.8 \%)$, encephalopathy 40 (1.2\%), and HCC 95 (2.9\%). Of the 59 patients with oesophageal varices, 15 had clinical bleeding; the rest were detected by endoscopy. The cumulative risk for the development of complications is shown in fig 1 . By the end of 10 years and 15 years of follow up, $8 \%$ and $12 \%$ of patients, respectively, had developed complications.

Table 2 Median age and hepatitis B e antigen/antibody to hepatitis $\mathrm{B}$ e antigen $(\mathrm{HBeAg} / \mathrm{anti}-\mathrm{HBe})$ status at the time of development of complications of cirrhosis and hepatocellular carcinoma

\begin{tabular}{|c|c|c|}
\hline & $\begin{array}{l}\text { Age (y) at the time } \\
\text { of complications } \\
\text { (median (range)) }\end{array}$ & $\begin{array}{l}\mathrm{HBeAg} / \text { anti-HBe } \\
(\% \text { anti-HBe }+ \text { ve) }\end{array}$ \\
\hline Ascites $(n=96)$ & $57.7(29-78.1)$ & $30 / 66(68.8 \%)$ \\
\hline $\operatorname{SBP}(n=30)$ & $60.0(32.2-78.0)$ & $7 / 23(76.7 \%)$ \\
\hline $\begin{array}{l}\text { Oesophageal varices } \\
(n=59)\end{array}$ & $54.3(25.4-82.3)$ & $14 / 45(76.3 \%)$ \\
\hline $\begin{array}{l}\text { Encephalopathy }(n=40) \\
\text { HCC }(n=95)\end{array}$ & $\begin{array}{l}58.5(27.6-83.1) \\
59(24.8-82)\end{array}$ & $\begin{array}{l}14 / 26(65 \%) \\
18 / 77(81.1 \%)\end{array}$ \\
\hline All complications $(n=170)$ & $57.2(24.8-83.1)$ & $45 / 125(73.5 \%)$ \\
\hline
\end{tabular}

$\mathrm{SBP}$, spontaneous bacterial peritonitis; HCC, hepatocellular carcinoma. 
Table 3 Liver biochemistry on presentation of patients with and without complications of cirrhosis

\begin{tabular}{llll}
\hline & $\begin{array}{l}\text { Patients who developed } \\
\text { complications of cirrhosis }\end{array}$ & $\begin{array}{l}\text { Patients without } \\
\text { complications of cirrhosis }\end{array}$ & p Value \\
\hline Albumin (g/l) & $34(17-50)$ & $45(18-58)$ & $<0.0001$ \\
ALT (U/l) & $59(11-3370)$ & $42(4-4820)$ & $<0.0001$ \\
Bilirubin ( $\mu \mathrm{mol} / \mathrm{l})$ & $18(3-323)$ & $11(1-553)$ & $<0.0001$ \\
AFP $(\mathrm{ng} / \mathrm{ml})$ & $17.5(1-32202)$ & $4(1-4991)$ & $<0.0001$ \\
\hline
\end{tabular}

Values are median (range).

ALT, alanine aminotransferase; AFP, $\alpha$ fetoprotein

Median age and HBeAg/anti-HBe status at the time of development of each complication are shown in table 2; $73.5 \%$ of patients were positive for anti-HBe when complications developed. As this might be related to the higher prevalence of anti-HBe positivity in the age groups when complications occurred, patients were stratified according to age. For patients under 50 years of age, the prevalence of anti-HBe positivity for patients who developed complications was significantly higher compared with that of patients with no complications $(73.1 \% \quad(38 / 52) \quad v \quad 56.4 \% \quad(1463 / 2596)$, respectively; $p=0.016$ ). For patients over 50 years of age, there was no significant difference in anti-HBe positivity between patients who developed complications and patients with no complications $(73.7 \%(87 / 118)$ v 80.1\% (374/467), respectively; NS).

\section{Factors associated with the development of complications \\ Demographics on presentation}

Males had a higher cumulative risk for the development of complications than females $(\mathrm{p}<0.0001)$. Patients who developed complications, compared with patients without complications, were older (median age 55 years (range 19-82) $v$ 38 years (range $1-85) ; p<0.0001$ ), had a higher chance of the presence of stigmata of chronic liver disease $(p<0.0001)$, and were more likely to present with hepatitis symptoms $(\mathrm{p}<0.0001)$.

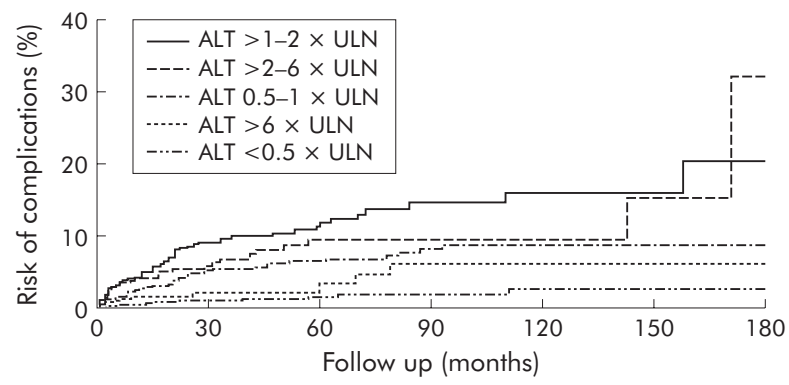

\begin{tabular}{lccccccc} 
No of patients & & & & & & \\
ALT $<0.5 \times$ ULN & 714 & 413 & 283 & 204 & 110 & 55 & 13 \\
ALT $0.5-1 \times$ ULN & 1006 & 472 & 281 & 176 & 85 & 44 & 12 \\
ALT $>1-2 \times$ ULN & 737 & 284 & 147 & 75 & 40 & 21 & 4 \\
ALT $>2-6 \times$ ULN & 479 & 230 & 113 & 63 & 35 & 17 & 3 \\
ALT $>6 \times$ ULN & 297 & 163 & 97 & 61 & 30 & 15 & 7 \\
& & & & & \\
\hline & ALT $<0.5$ & ALT 0.5-1 & ALT $>1-2$ & ALT $>2-6$ & ALT $>6$ \\
& $\times$ ULN & $\times$ ULN & $\times$ ULN & $\times$ ULN & $\times$ ULN \\
\hline ALT $<0.5 \times$ ULN & - & $<0.0001$ & $<0.0001$ & $<0.0001$ & 0.039 \\
ALT $0.5-1 \times$ ULN & $<0.0001$ & - & 0.0004 & NS & NS \\
ALT $>1-2 \times$ ULN & $<0.0001$ & 0.0004 & - & NS & 0.0006 \\
ALT $>2-6 \times$ ULN & $<0.0001$ & NS & NS & - & 0.013 \\
ALT $>6 \times$ ULN & 0.039 & NS & 0.0006 & 0.013 & -
\end{tabular}

Figure 2 Cumulative risk of development of complications stratified according to alanine aminotransferase (ALT) levels on presentation. The table depicts $p$ values for comparisons between different groups of patients. ULN, upper limit of normal.

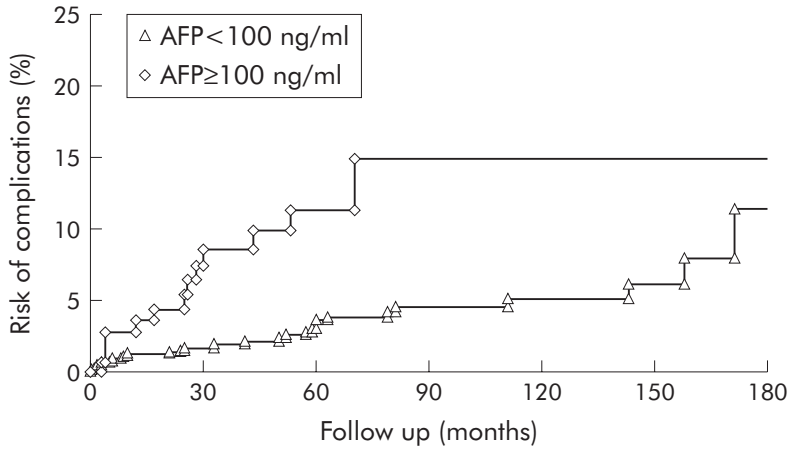

No of patients

$\begin{array}{lccccccc}\text { AFP }<100 & 1199 & 621 & 363 & 229 & 130 & 68 & 15 \\ \mathrm{ng} / \mathrm{ml} & & & & & & & \\ \begin{array}{l}\mathrm{AFP} \geq 100 \\ \mathrm{ng} / \mathrm{ml}\end{array} & 153 & 81 & 53 & 33 & 12 & 5 & 2\end{array}$

Figure 3 Cumulative risk of development of complications in patients with $\alpha$ fetoprotein (AFP) levels $\geqslant 100 \mathrm{ng} / \mathrm{ml}$ and with AFP $<100 \mathrm{ng} / \mathrm{ml}$ during acute exacerbation of hepatitis $B$ virus infection.

Liver biochemistry and AFP

Patients who developed complications had significantly lower median albumin levels, higher median ALT levels, higher median bilirubin levels, and higher median AFP levels on presentation compared with patients without complications (table 3). However, median bilirubin and AFP levels for those who developed complications were still within normal limits.

To determine the risk for the development of complications with respect to ALT levels, patients were stratified into five groups according to ALT levels on presentation: $<0.5 \times \mathrm{ULN}$ $(\mathrm{n}=714) ; 0.5-1 \times$ ULN $(\mathrm{n}=1006) ;>1-2 \times \operatorname{ULN}(\mathrm{n}=737)$; $>2-6 \times$ ULN $(\mathrm{n}=479) ;$ and $>6 \times$ ULN $(\mathrm{n}=297)$. The cumulative risk for the development of complications was highest for patients with ALT levels of $1-2 \times$ ULN (fig 2). In addition, patients with ALT levels of $0.5-1 \times$ ULN already had a significantly increased risk of complications compared with patients with ALT levels $<0.5 \times$ ULN. The risk of complications started to decrease for patients with ALT levels of $2-6 \times$ ULN and became very low for patients with ALT levels above $6 \times$ ULN.

The effect of ALT levels during follow up on the cumulative risk for the development of complications was also calculated for patients with at least three ALT readings. Patients were categorised by median ALT levels according to the same criteria adopted above. As there were only nine patients with median ALT levels more than $6 \times$ ULN, they were grouped with patients with ALT levels $>2-6 \times$ ULN. Again, patients with ALT levels $>1-2 \times$ ULN had the highest risk for the development of complications $(\mathrm{p}<0.0001$ and $\mathrm{p}=0.0027$ compared with patients with ALT $<0.5 \times$ ULN and patients with ALT levels $0.5-1 \times$ ULN, respectively). Patients with ALT levels of $0.5-1 \times$ ULN also had a higher risk for the development of complications compared with patients with 
ALT levels $<0.5 \times$ ULN $(p=0.0071)$. There were no significant differences in the risk for development of complications when patients with ALT levels $>2-6 \times$ ULN were compared with patients with ALT levels $<0.5 \times$ ULN and those with ALT levels 0.5-1 $\times$ ULN.

\section{$\mathrm{HBeAg}$ status on presentation}

There was no significant difference in the cumulative risk for the development of complications between HBeAg positive patients and anti-HBe positive patients $(p=0.12)$. This was also true when each type of complication was analysed separately.

\section{Effect of exacerbation}

The effect of exacerbation on the development of complications was analysed with respect to the number of episodes of exacerbation, duration of exacerbation, peak ALT levels, and peak AFP levels. The only significant risk factor was peak AFP levels of $100 \mathrm{ng} / \mathrm{ml}$ or more during or after an exacerbation $(p=0.0001$ compared with patients with AFP level less than $100 \mathrm{ng} / \mathrm{ml}$ ) (fig 3).

\section{HBV DNA levels}

HBV DNA levels were measured in 2332 patients. Of these, 112 had paired serum samples before and after HBeAg seroconversion. In addition, $525 \mathrm{HBeAg}$ positive patients and 1695 anti-HBe positive patients had samples at the last follow up for HBV DNA assays. Details of HBV DNA levels measured by Digene Hybrid Capture assay are shown in table 4.

Median HBV DNA levels of the 1695 anti-HBe positive patients, as determined by the Cobas Amplicor HBV Monitor test, was 7250 copies $/ \mathrm{ml}$ (range $<200-1.7 \times 10^{9}$ ). Only 386 patients $(22.8 \%)$ had undetectable HBV DNA levels. HBV DNA levels were $<10^{3},>10^{3}-10^{4},>10^{4}-10^{5}$, and $>10^{5}$ copies $/ \mathrm{ml}$ in $183(10.8 \%), 320$ (18.9\%), 259 (15.3\%), and $547(32.3 \%)$ patients, respectively.

HBV DNA levels were measured in 110 patients with complications: 21 patients before the complications developed (range 0.2-8.25 months); nine at the time of the complications; and 80 after the complications developed (range 0.41-193.5 months). Median HBV DNA level was $0.323 \times 10^{6}$ copies $/ \mathrm{ml}$ (range $<0.142-1700 \times 10^{6}$ copies $/ \mathrm{ml}$ ). Forty eight patients $(43.6 \%)$ had HBV DNA levels undetectable by the Digene Hybrid Capture assay. The Cobas Amplitor HBV Monitor test was performed in 45 of these patients. Thirteen $(28.9 \%)$ patients had undetectable HBV DNA (that is, $<200$ copies $/ \mathrm{ml}$ ). HBV DNA levels (copies $/ \mathrm{ml}$ ) of the remaining 32 patients were as follows: $<10^{3}$ in two patients $(4.4 \%) ;>10^{3}-10^{4}$ in 12 patients $(26.7 \%) ;>10^{4}-10^{5}$ in 10 patients $(22.2 \%)$; and $>10^{5}$ in eight patients $(17.8 \%)$.

\section{Independent factors associated with development of complications and poor survival}

Using the Cox proportional hazards model, male sex $(p<0.0001)$, presence of stigmata of chronic liver disease $(p=0.045)$, increasing age $(p<0.0001)$, low albumin level on presentation $(\mathrm{p}<0.0001)$, and high AFP level on presentation $(p=0.001)$ were found to be independent factors associated with a higher cumulative risk for the development of complications.

For survival analysis, male sex $(p=0.004)$, presence of hepatitis symptoms $(p=0.02)$, increasing age $(p<0.0001)$, and low albumin level on presentation $(\mathrm{p}<0.0001)$ were found to be independent factors associated with a shorter actuarial survival.

\section{DISCUSSION}

The present study was limited by the relatively short period of follow up even though 307 patients $(10.0 \%)$ were followed up for more than 10 years. Another limitation of the study was the absence of histological assessment. However, the end points of our study, the development of cirrhosis related complications and HCC, are of great clinical and prognostic relevance.

Several findings from the present study have direct implications for criteria for the treatment of $\mathrm{CHB}$ in the future. Firstly, the risk of complications increased as ALT levels on presentation increased from $>0.5 \times$ ULN to $2 \times$ ULN. In contrast, patients with ALT levels above $6 \times$ ULN had a significantly lower risk for the development of complications (fig 2). These findings were confirmed using median ALT levels of patients during subsequent follow up. Acute exacerbations and high ALT levels (for example, $>2 \times$ ULN) probably signify acute injuries to the liver which may not lead to permanent damage. This is probably analogous to the situation in acute viral hepatitis. However, in patients with only mild elevation of ALT, including those with ALT levels in the upper range of normal, the immune attack on the liver might be more insidious and chronic, leading eventually to more severe and permanent damage.

In the study of Kim et al showing an increased risk of mortality from liver disease in patients with ALT levels in the upper range of normal, it was suggested that the normal range of serum aminotransferase concentrations should be lowered in populations in which liver disease are common. ${ }^{8}$ Even though the authors did not test their subjects for hepatitis B or C markers, their findings confirm ours. The present guidelines for treatment suggest that only patients with ALT levels $>2 \times$ ULN should be treated..$^{5-7}$ This would exclude patients with the highest risks for the development of complications from treatment.

Secondly, in the Asian population, disease activity continues to progress in a proportion of patients after HBeAg seroconversion. Median age for the development of complications in our patients was 57.2 years (table 2). Median age of HBeAg seroconversion was 35 years. More than two thirds of the patients were already anti-HBe positive when they developed complications. The cumulative risk for the development of complications was comparable between patients positive for HBeAg and for anti-HBe on presentation. A Taiwan study by Yang et al. claimed that HBeAg positivity was associated with an increased risk of HCC. ${ }^{12}$ HBeAg status of

Table 4 Hepatitis B virus (HBV) DNA levels of 2332 patients measured by Digene Hybrid Capture assay

\begin{tabular}{|c|c|c|c|c|}
\hline & \multicolumn{2}{|c|}{112 patients with paired serum } & \multicolumn{2}{|c|}{2220 patients with serum at last follow up } \\
\hline & $\begin{array}{l}\text { HBeAg+ve phase } \\
(n=112)\end{array}$ & $\begin{array}{l}\text { Anti-HBe+ve phase } \\
(\mathrm{n}=112)\end{array}$ & $\begin{array}{l}\text { HBeAg+ve } \\
(n=525)\end{array}$ & $\begin{array}{l}\text { Anti-HBe+ve } \\
(n=1695)\end{array}$ \\
\hline $\begin{array}{l}\text { Undetectable HBV DNA (\%) } \\
\text { HBV DNA level } \\
\left(\times 10^{6} \text { copies } / \mathrm{ml}\right) \\
\text { (median (range)) }\end{array}$ & $\begin{array}{l}27(24.11) \\
4.15(<0.142-803.87)^{*}\end{array}$ & $\begin{array}{l}73(65.18) \\
<0.142(<0.142-434.58)^{*}\end{array}$ & $\begin{array}{l}102(19.4) \\
12.99(<0.142-1700)+\end{array}$ & $\begin{array}{l}1271(75.0) \\
\quad<0.142(<0.142-1700) \dagger\end{array}$ \\
\hline
\end{tabular}

$\mathrm{HBe} A g$, hepatitis $B$ e antigen; anti-HBe, antibody to hepatitis $B$ e antigen. ${ }^{*} \mathrm{p}<0.001 ; \dagger p<0.001$. 
the patients in this study however was checked only at the time of enrolment whereas the development of HCC was observed during the subsequent 10 years of follow up. HBeAg/anti-HBe status at the time of development of HCC was not assessed. This study therefore can provide no clue as to the HBeAg status of patients at the time of HCC development. Another smaller Taiwan study found that although HBeAg seroconversion confers a favourable outcome in some patients, active hepatitis can occur after HBeAg seroconversion, leading to cirrhosis and HCC. ${ }^{13}$ McMahon et $a l$, in their study, found that "seroconversion from HBeAg to anti-HBe, and even loss of hepatitis B surface antigen, did not protect patients from development of hepatocellular carcinoma" ${ }^{\prime 14}$ These latter two studies confirm the findings of the present study, that the majority of cirrhosis related complications and HCC develop after HBeAg seroconversion. The onset of cirrhosis occurs during the prolonged process of HBeAg seroconversion in Asian patients. ${ }^{15}$ Cirrhosis will continue to worsen or develop after HBeAg seroconversion. ${ }^{16-18}$ Thus HBeAg seroconversion should only be regarded as a step towards viral suppression, and therapy may need to be continued after HBeAg seroconversion.

Thirdly, progression of cirrhosis is more likely to be related to the low level of viraemia in a large proportion of patients who are anti-HBe positive. In the current study, only $22.8 \%$ of anti-HBe patients had undetectable HBV DNA levels by the PCR based assay; $32.3 \%$ had more than $10^{5}$ copies $/ \mathrm{ml}$. (That the wild-type virus is as likely to cause complications as the precore mutants have been analysed in a separate study ${ }^{19}$.)

Among the $56 \%$ of patients with complications in whom HBV DNA levels were undetectable by the Digene Hybrid Capture assay, over 70\% had HBV DNA levels detectable by the Amplicor HBV Monitor test. Twenty nine per cent of patients had undetectable HBV DNA (that is, <200 copies/ $\mathrm{ml}$ ). This is evidence against the proposal that disease progression is unlikely once HBV DNA levels become less than $10^{5}$ copies $/ \mathrm{ml}^{20}$ Our findings support the conclusion of Chu and colleagues ${ }^{21}$ that there is no cut off HBV DNA value for differentiating active from inactive disease in $\mathrm{HBeAg}$ negative patients. This implies that prolonged and maximal suppression of HBV DNA to levels below the detection limit of PCR based assays may be necessary to reduce the risk of complications.

In conclusion, prolonged low level viraemia causing insidious and continual liver damage, as reflected by relatively mild elevations in ALT levels, is the most likely pathway leading to the development of complications for Asian patients with CHB. Long term antiviral therapy aiming at maximal suppression of HBV even after HBeAg seroconversion may be required for Asian patients.
Authors' affiliations

M-F Yuen, H-J Yuan, D K-H Wong, J C-H Yuen, W-M Wong, A O-O

Chan, B C-Y Wong, K-C Lai, C-L Lai, Department of Medicine, The

University of Hong Kong, Queen Mary Hospital, Hong Kong

Conflict of interest: None declared.

\section{REFERENCES}

1 Lee WM. Hepatitis B virus infection. N Engl J Med, 1997;337:1733-45.

2 Lai CL. Chronic hepatitis B in Hong Kong: immunization strategies for the control of hepatitis B virus infection. In: Zuckerman, eds. Hepatitis B in the Asian-Pacific region vol. 1 screening, diagnosis and control. London: Royal College of Physicians, 1997:79-87.

3 Beasley RP, Hwang LY. Overview on the epidemiology of hepatocellular carcinoma. In: Hollinger FB, Lemon SM, Margolis $H$, eds. Viral hepatitis and liver diseases. Baltimore: Williams and Wilkins, 1991:532-5.

4 Maddrey WC. Hepatitis B-an important public health issue. Clin Lab 2001;47:51-5.

5 Lok ASF, McMahon BJ. Chronic hepatitis B. Hepatology 2001;34:1225-41.

6 EASL Jury. EASL international consensus conference on hepatitis B. 13-14 September, 2002: Geneva, Switzerland, Consensus statement (long version). $J$ Hepatol 2003;38:533-40.

7 Liaw YF, Leung N, Guan R, et al. Asian-Pacific consensus statement on the management of chronic hepatitis B: An update. J Gastroenterol Hepatol 2003:18:239-45.

$8 \mathrm{Kim} \mathrm{HC}, \mathrm{Nam} \mathrm{CM}$, Jee SH, et al. Normal serum aminotransferase concentration and risk of mortality from liver diseases: prospective cohort study. BMJ 2004;328:983-8.

9 Lai CL, Rosmawati M, Lao J, et al. Entecavir is superior to lamivudine in reducing hepatitis $B$ virus DNA in patients with chronic hepatitis $B$ infection. Gastroenterology 2002;123:1831-8.

10 Lai CL, Leung NWY, Teo EK, et al. Results of a one-year international phase llb comparative trial of telbivudine, lamivudine, and the combination, in patients with chronic hepatitis B. Hepatology 2003;38(suppl 1):72A.

11 Yuen MF, Hui CK, Cheng CC, et al. Long-term follow-up of interferon-alpha treatment in Chinese patients with chronic hepatitis B infection: the effect on $\mathrm{HBeAg}$ seroconversion and the development of cirrhosis-related complications. Hepatology 2001;34:139-45.

12 Yang HI, Lu SN, Liaw YF, et al. Hepatitis B e antigen and the risk of hepatocellular carcinoma. N Engl J Med 2002;347:168-74.

13 Hsu YS, Chien RN, Yeh CT, et al. Long-term outcome after spontaneous $\mathrm{HBeAg}$ seroconversion in patients with chronic hepatitis B. Hepatology 2002;35:1522-7.

14 McMahon BJ, Holck P, Bulkow L, et al. Serologic and clinical outcomes of 1536 Alaska natives chronically infected with hepatitis B virus. Ann Intern Med $2001 ; 135: 759-68$

15 Eddleston AL. The natural history of hepatitis B virus infection. Chemioterapia 1988;7(suppl 3):5-8.

16 Liaw YF, Tai DI, Chu CM, et al. The development of cirrhosis in patients with chronic type B hepatitis: A prospective study. Hepatology 1988;8:493-6.

17 Chen DS. Natural history of chronic hepatitis B virus infection: New light on an old story. J Gastroenterol Hepatol 1993;8:470-5.

18 Merican I, Guan R, Amarapuka D, et al. Chronic hepatitis B virus infection in Asian countries. J Gastroenterol Hepatol 2000;15:1356-61.

19 Yuen MF, Sablon E, Yuan HJ, et al. Relationship between the development of precore and core promoter mutations and $\mathrm{HBeAg}$ seroconversion in chronic hepatitis B. J Infect Dis 2002;186:1335-8.

20 Lok ASF, Heathcote EJ, Hoofnagle JH. Management of hepatitis B: 2000summary of a workshop. Gastroenterology $2001 ; 120: 1828-53$.

21 Chu CJ, Hussain M, Lok AS. Quantitative serum HBV DNA levels during different stages of chronic hepatitis B infection. Hepatology 2002;36:1408-15 